\title{
QUE PERSPECTIVAS PARA A ECONOMIA PORTUGUESA NO QUADRO DA UNIÃO ECONÓMICA E MONETÁRIA?
}

\author{
V. Xavier Pintado*
}

\section{INTRODUÇÃO}

O Mercado Único Europeu, de que fazemos parte, tem vindo a remover os obstáculos à livre circulação de mercadorias, pessoas, serviços e capitais e à liberdade de estabelecimento de empresas de outros países membros, com vista a realizar um mercado europeu integrado, como se fora o de um único país. Entretanto, a União Monetária visa chegar a uma moeda única, que reduza os custos de transacção e assegure a transparência dos preços em todo esse vasto mercado.

O embarcar num tal projecto constitui uma das decisões de maior alcance e carregada de consequências que um Estado pode tomar no campo económico. Uma coisa é certa, e essa é a conclusão tanto da teoria como a lição da experiência histórica: a abertura dos mercados e o aprofundamento da integração económica é fonte de melhoria de bem estar económico e de criação de riqueza. O que não é certo, nem a teoria económica permite dilucidar, é a forma como se distribui esse acréscimo de bem estar entre países e regiões.

A nossa pergunta, hoje, consiste nisto: o que vai suceder à economia portuguesa, ou o que podemos esperar que lhe suceda, ao participar nesse projecto de integração progressiva?

Vão os nossos padrões de vida convergir ou aproximar-se dos do centro e norte da Europa ou, ao contrário, vai a nossa indústria, frágil e tecnologicamente menos avançada, ser abalada ou destruída pela concorrência proveniente de economias mais desenvolvidas ou mais dinâmicas que a nossa? E vão as nossas empresas expandir-se e desenvolver-se, aumentando a penetração dos seus produtos nos mercados externos, ou vai o controlo de muitos sectores de actividade passar para mãos estrangeiras?

Deve dizer-se, à partida, que nem a teoria económica nem a análise histórica nos permitem dar respostas claras e definitivas a estas perguntas. ${ }^{1}$ Há, porém,

* Faculdade de Ciências Económicas e Empresariais da Universidade Católica Portuguesa. 
vários pontos que a análise económica e o exame de paralelos históricos ajudam a clarificar.

A análise que aqui pretendemos desenvolver vai ser sobretudo de carácter empírico e histórico-institucional, dada a natureza inconclusiva da teoria em face da maior parte dos problemas que nos propomos abordar.

\section{A DIVISÃO NORTE-SUL NA EUROPA}

Começaremos por uma tentativa de caracterização da economia portuguesa, procurando situar Portugal no quadro europeu em termos de níveis de bem estar e desenvolvimento.

Se tomarmos um indicador agregado, como o PIB per capita expresso em termos de poder de compra comparado, encontramos a seguinte distribuição dos 12 países que, até fins de 1994, faziam parte da União Europeia em relação à média comunitária para os anos de 1991 a 1993, bem como a posição relativa dos EUA e do Japão.

\section{Quadro I}

PIB POR HABITANTE — 1991-1993

\begin{tabular}{|l|c|c|c|}
\hline & \multicolumn{3}{|c|}{ \% da média comunitária } \\
\hline UE & 1991 & 1992 & 1993 \\
Luxemburgo & 100 & 100 & 100 \\
França & 130.9 & 132.1 & 138.8 \\
Dinamarca & 114.9 & 113.1 & 116.3 \\
Bélgica & 109.7 & 106.8 & 113.3 \\
Alemanha & 107.4 & 109.8 & 111.8 \\
Holanda & 106.7 & 107.6 & 107.5 \\
Itália & 103.3 & 102.8 & 106.7 \\
Reino Unido & 106 & 105.4 & 102 \\
Irlanda & 98.4 & 96.9 & 99.4 \\
Espanha & 74.1 & 76.9 & 75.5 \\
Portugal & 78.8 & 77.6 & 73.8 \\
Grécia & 55.5 & 67.5 & 64.5 \\
EUA & 48.8 & 50.2 & 50.9 \\
Japão & 141.1 & 144.2 & 149.6 \\
\hline
\end{tabular}

Fonte: Eurostat

(*) A preços correntes e em paridades de poder de compra 
Torna-se claro, do Quadro I, que os quatro países periféricos - Portugal, Espanha, Grécia e Irlanda - aparecem com rendimentos claramente inferiores à média, embora com graus diferentes de distanciamento dos valores relativos aos países do centro e norte da Europa. O único país do sul a fugir a esta regra é a Itália, mas, ainda aí, é a Itália do norte e não a Itália do sul que para tal contribui.

Portugal aparece aí, não no extremo da "cauda da Europa" (que hoje é ocupado pela Grécia) mas, ainda assim, na "cauda". Com um rendimento per capita da ordem dos 64,5\% da média comunitária em 1993 (67,5\% em 1992), encontramo-nos algo abaixo da posição da Espanha e da Irlanda com cerca de 3/4 da mesma média.

\section{Factores explicativos}

Diversos factores têm sido invocados para explicar esta situação de menor desenvolvimento da periferia em relação ao "centro", ou do sul em relação ao norte, desde a própria localização periférica (custos de periferia), à abundância de recursos naturais, especialmente de ferro e carvão, à estrutura fundiária e a factores de índole cultural como a ausência de espírito mercantil, "over extension", e, mesmo, a factores religiosos, como em Max Weber com a sua "protestant ethic".

$\mathrm{O}$ que pretendemos aqui realçar é o facto de a divisão norte/sul em termos económicos ter sido, na Europa, um fenómeno ou "acidente histórico" localizado no tempo. Consistiu no "take-off" tardio, ou entrada tardia da "periferia" na 1. ${ }^{a}$ Revolução Industrial, não sendo o resultado de uma mais reduzida velocidade de crescimento ao longo das últimas décadas. Bem ao contrário.

Os países do sul não participaram no impulso de desenvolvimento conferido à Europa pela chamada Revolução Industrial no primeiro grande período de crescimento sustentado da história da humanidade: o que se estendeu de meados do Séc. XIX à $1 .{ }^{\mathrm{a}}$ Guerra Mundial.

O seu "take-off" tardio levou-os a participar apenas no segundo grande período de expansão dessa economia, que foi o quarto de século do início dos anos 50 ao $1 .^{\circ}$ choque petrolífero, em meados dos anos 70 .

Mas, nesse período, registaram um crescimento bem mais rápido que o do centro e norte da Europa e que o do conjunto dos países industriais, tendo o ritmo de crescimento vindo a acelerar de década para década em Portugal, na Espanha e na Grécia, aumentando o diferencial positivo de crescimento em relação à média europeia, e à da OCDE, até atingir taxas superiores em $50 \%$ às da média europeia no período de $1968 / 73$. 


\section{Quadro II \\ NÍVEIS RELATIVOS DE RENDIMENTO PER CAPITA \\ EM TERMOS DE PODER DE COMPRA}

$1955 / 1989$

\begin{tabular}{|l|c|c|c|c|c|c|}
\hline & 1955 & 1960 & 1970 & 1977 & 1980 & 1989 \\
\hline Portugal & 19 & 23 & 32 & 40 & 36 & 36 \\
Espanha & 31 & 33 & 49 & 53 & 41 & 48 \\
Brasil & 15 & 18 & 18 & 24 & 23 & - \\
Israel & 32 & 41 & 52 & 53 & 48 & - \\
Coreia do Sul & 12 & 12 & 17 & 23 & 31 & - \\
Japão & 23 & 33 & 64 & 67 & 67 & 75 \\
Estados Unidos & 100 & 100 & 100 & 100 & 100 & 100 \\
\hline
\end{tabular}

Fonte: Robert Summers and Alan Heston, «Improved International Comparisons of Real Product and its Composition, 1950/80m, in Review of Income and Wealth, vol. 30, June 1984 OECD in Figures.

No caso específico de Portugal foi, assim, possível elevar o rendimento per capita de $1 / 5$ para 2/5, ou, mais precisamente, de $19 \%$ para $40 \%$ do dos Estados Unidos de meados dos anos 50 para meados dos anos 70.

Ao mesmo tempo a Espanha passou de um rendimento por cabeça da ordem dos $30 \%$ do dos EUA para um pouco mais de metade desse rendimento. Evolução semelhante se verificou nos demais países do Sul: Grécia, Turquia e Jugoslávia.

Ao mesmo tempo mostrou-se possível a estes países reconciliar taxas de crescimento e de emprego relativamente elevadas com o equilíbrio externo das suas economias e com um grau também elevado de estabilidade dos preços, especialmente em Portugal.

Durante esse período (1950/75) todos estes países puderam beneficiar de uma abertura dos mercados externos devido à liberalização das trocas asseguradas pelo GATT, a CE e a EFTA. E esse foi um dos factores que tornou possível o crescimento da produção por eles registado, tendo a expansão destas economias sido, em larga medida, suscitada ou estimulada pela procura externa, como mostra $o$ crescimento das suas exportações.

\section{A MAIOR VULNERABILIDADE DO SUL AOS CHOQUES EXTERNOS}

A década de 1975/85 foi, entretanto, marcada pelos efeitos dos dois choques petrolíferos e pelas recessões de 1974/75 e de 1980/82, bem como pelo esforço de ajustamento que esses choques impuseram aos países importadores de petróleo. 
Para os países do Sul foi um período de retrocesso ou divergência em matéria de crescimento, com o cavar de novo do fosso dos rendimentos per capita que os separava dos países industrialmente mais avançados, tendo o rendimento per capita em Portugal retrogradado de $40 \%$ do dos EUA para $36 \%$ apenas.

Ao mesmo tempo a segunda metade dos anos 70 e primeira metade dos anos 80 revelaram a maior vulnerabilidade destas economias aos choques externos, com uma deterioração dos seus termos de troca, um desequilíbrio mais acentuado das balanças de pagamentos e tensões inflacionistas mais pronunciadas que as que se verificaram nos países industriais.

Assim, na prática, a generalidade dos restantes países da OCDE necessitou apenas de quatro anos após o primeiro choque petrolífero para restabelecer o equilíbrio das suas balanças de pagamentos correntes, o que conseguiram em geral em 1978 e a Suíça em 1976. Isto com um aumento do volume das suas exportações de mercadorias de 5\% ao ano apenas. Entretanto, os países do sul da Europa teriam tido de duplicar as suas exportações em termos reais para conseguirem equilibrar as suas balanças de pagamentos no mesmo período de tempo.

E porquê? Em virtude, sobretudo, da diferente estrutura da sua produção e das suas exportações e não apenas por serem países mais dependentes da importação de energia.

É que, enquanto os países industrialmente mais avançados puderam elevar o preço unitário das suas exportações de modo a compensar em boa parte o aumento dos preços da energia, o mesmo não foi possível às economias menos avançadas do sul da Europa. Estas, com efeito, além de terem de pagar uma factura de energia mais pesada, sofreram igualmente um aumento dos preços dos produtos intermédios (produtos químicos e outros) e dos bens de equipamento que importavam dos países mais avançados do Norte.

Assim, no caso específico de Portugal, enquanto o preço unitário das suas importações aumentou 7,8 vezes entre 1974 e 1982, o preço unitário das exportações foi multiplicado apenas por 5,7. Donde resultou uma deterioração dos termos de troca de $27 \%$.

Ao mesmo tempo, os países do Sul da Europa experimentaram maior dificuldade no processo de ajustamento das suas economias e na contenção das tensões inflacionistas, incorrendo em aumentos anuais de preços bastante superiores aos da média dos países industriais.

Serve esta nota para chamar a atenção para a maior exposição destes países aos choques externos e para a assimetria dos efeitos destes sobre as diferentes regiões da Europa no quadro de um mercado mais integrado e, naturalmente, da União Monetária. 


\section{A EXPERIÊNCIA HISTÓRICA DA ASSIMETRIA DOS EFEITOS DA UNIFICAÇÃO DE MERCADOS}

Que lição podemos tirar das diferentes experiências históricas de integração ou unificação de mercados (Zollverein, unificação da Itália e unificação dos E.U.A.)?

Essa experiência foi, em geral, considerada negativa para as regiões menos desenvolvidas.

No caso do Zollverein, instituído em 1834, considera-se que o estabelecimento de uma união aduaneira beneficiou sobretudo os estados ou "landers" da Prússia e da Saxónia, que aumentaram a sua quota de mercado sobretudo à custa de desvio do comércio realizado com o estrangeiro. A agricultura dos Estados do sul beneficiou também, mas a industrialização dessas regiões parece ter sido dificultada pela unificação aduaneira.

No caso da unificação da Itália, os efeitos perversos da eliminação dos obstáculos ao comércio entre o norte e o sul parecem ter sido ainda mais notórios para o Mezzogiorno.

Um efeito análogo parece ter exercido a unificação levada a efeito nos E.U.A. após a Guerra da Secessão, onde a indústria emigrou em certa medida dos Estados do Sul para o "Sun-belt".

A experiência das uniões monetárias do século XIX é pouco elucidativa a este respeito, quer devido à curta duração da maioria delas, quer ao facto de apenas uma - a União Latina - ter incluído países do sul: a Itália e, por um período curto, a Grécia. Mas nem a União Monetária Alemãa, constituída pelos Estados do Zollverein com a Áustria, nem a União Monetária Escandinava, constituída pela Dinamarca, Noruega e Suécia, nos fornecem elementos suficientes para podermos julgar os efeitos das uniões monetárias sobre o desenvolvimento dos países ou zonas periféricas.

A União Monetária que mais durou - a estabelecida entre o Reino Unido e a Irlanda, que subsistiu ao longo de cerca de século e meio - é, porém, julgada de modo assaz negativo pelos Irlandeses, não tendo levado à convergência de níveis de vida ou rendimento per capita entre os dois países.

Esta experiência de unificação de economias que ainda não tinham realizado o "take-off", e com uma industrialização muito incipiente, com economias de regiões mais avançadas suscita, no entanto, dois tipos de questões. Uma é a de saber se as lições que dela resultam é aplicável à integração ou unificação de mercados em condições muito diversas, em que o investimento estrangeiro e as possibilidades de "catching-up" tecnológico podem exercer uma acção completamente diversa sobre as regiões periféricas do que aquela que exerceram no século passado e início do presente. Esta pergunta é tanto mais pertinente quanto a análise dos efeitos da abertura ao exterior de economias que no passado se tinham mantido fechadas revela um sucesso claramente superior, em matéria de cresci- 
mento, das economias que expuseram as suas indústrias à concorrência do exterior do que o daquelas que continuaram a proteger a sua produção da concorrência externa.

A outra pergunta que se põe é a de saber se os custos ou efeitos negativos da periferia não podem ser minorados ou compensados por transferências de fundos do centro para a periferia, tendentes a melhorar as infra-estruturas de transportes e comunicações e as condições de educação e saúde nas regiões mais desfavorecidas.

Por tudo isto, parece-nos mais relevante o exame das experiências mais recentes de abertura de mercados e de integração de espaços que incluem economias em estádios diversos de desenvolvimento.

\section{A EXPERIÊNCIA DA PARTICIPAÇÃO DE PORTUGAL NA EFTA E A EXPERIÊNCIA DA CEE}

Portugal foi membro fundador da EFTA, facto que the assegurou desde o final da década de 50 o acesso a um mercado de 90 milhões de consumidores ricos, permanecendo nesta organização durante um quarto de século: até ao final de 1985, quando aderiu à CEE.

A participação de Portugal na EFTA assegurou-lhe o acesso a um vasto mercado que incluía o seu principal parceiro comercial - a Inglaterra - , ao mesmo tempo que lhe conferiu a possibilidade de continuar a proteger os segmentos mais vulneráveis da sua indústria mediante o mecanismo do Anexo $\mathrm{G}$ à Convenção de Estocolmo e por outros meios.

Mas essa participação coincidiu com um período de crescimento rápido da economia mundial e da nossa economia, que favoreceu grandemente mediante a abertura de mercados externos que proporcionaram um aumento muito mais acentuado das nossas exportações para os demais países membros do que o das nossas exportações totais, não sucedendo o mesmo com as nossas importações do interior dessa área.

Nesse período, com efeito, o valor das nossas exportações para a EFTA, expresso em dólares, aumentou 38 vezes, contra um aumento de 18 vezes das nossas exportações totais, enquanto as importações da EFTA se multiplicaram por 13 apenas. Entretanto, a parte da indústria no produto interno elevou-se de $27 \%$ para $30 \%$ e as exportações de produtos industriais passaram de $50 \%$ das exportações totais a $73 \%$ dessas mesmas exportações.

Não há também evidência de destruição significativa de indústrias pela concorrência externa durante esse período, enquanto indústrias como a têxtil e do vestuário, da pasta de papel e do concentrado de tomate conheceram uma expansão muito acentuada. 
Esta experiência, porém, não pode ser tomada como paralelo para a que estamos a fazer neste momento, de inserção num vasto mercado unificado, não apenas de produtos industriais, mas de bens, serviços e capitais, com liberdade de circulação de mão-de-obra, liberdade de estabelecimento e unificação de regras de concorrência.

A este propósito, é mais significativa a nossa própria experiência, bem como a de outros países periféricos, como a Grécia e Irlanda, na CEE.

\section{Tendências observadas nos países periféricos}

O período relativamente curto decorrido desde o $3 .^{\circ}$ alargamento da CEE - o alargamento ao Sul — não é suficiente para permitir tirar conclusões, digamos "históricas", no que respeita àquilo que podemos esperar da participação destas economias na CEE: menos de uma década para Portugal e Espanha e cerca de década e meia para a Grécia, com uma parte significativa desse período decorrida em regime de transição. A Irlanda, essa, aderiu à $\mathrm{CEE}$ há um pouco mais de duas décadas: em 1 de Janeiro de 1973.

Em todos estes países, porém, se observou um movimento de convergência real, ou aproximação manifesta dos seus rendimentos por cabeça da média da CEE, mantendo-se embora esses rendimentos sensivelmente abaixo dessa média.

Entretanto a análise comparativa das taxas de crescimento no "Norte" e no "Sul" tende a mostrar que, em períodos de expansão da economia europeia, os níveis de rendimento por cabeça dos países periféricos tendem a convergir para os dos países membros industrialmente mais avançados e, em períodos de recessão, tendem a divergir. Foi isto que sucedeu na $2^{\mathrm{a}}$ metade dos anos 70 e no início dos anos 80 , na sequência dos dois choques petrolíferos e das recessões que se lhes seguiram.

A balança de pagamentos correntes dos países periféricos, por seu turno, deteriorou-se, mas a melhoria da balança de capitais em geral compensou essa deterioração.

No que toca às alterações da estrutura industrial diversos estudos tendem a revelar um acréscimo do comércio intra-industrial (ou do mesmo tipo de produtos), o que sugere uma aproximação do tipo de estruturas produtivas com a integração. Mas esse efeito não se observou nos EUA, onde a unificação de mercados parece ter acentuado a especialização produtiva dos vários Estados ou regiões.

Numa $1^{\text {a }}$ fase a integração de economias parece tender a acentuar a especialização produtiva existente, reforçando as vantagens comparativas de que cada país já disfruta. Só com o andar do tempo e a concorrência do exterior - e com o esforço de investimento e "catching-up" tecnológico - é que se vão adquirindo novas vantagens comparativas e a estrutura produtiva dos países industrialmente 
menos avançados tende a diversificar-se, fazendo surgir novos "clusters" ou especializações produtivas.

Entretanto a experiência irlandesa revela que uma parte significativa das novas produções e, em particular da produção exportável, é realizada por empresas controladas por capital estrangeiro. Cerca de $4 / 5$ do acréscimo de exportações registado desde a adesão da Irlanda à CEE foram conseguidos por empresas com maioria de capital ou controlo externo e apenas $1 / 5$ por empresas controladas por irlandeses. Neste aspecto, porém, o caso irlandês é específico e resulta em parte da política seguida de concessão de incentivos ao investimento estrangeiro, nomeadamente $o$ orientado para a exportação. $O$ que tem levado a falar na transformação da economia irlandesa (especialmente no que toca à actividade industrial) numa economia de enclave.

\section{A experiência portuguesa pós-adesão à CE}

A experiência de Portugal após a adesão a CE, em 1 de Janeiro de 1986, entretanto, revela:

a) Uma forte convergência real, com uma taxa média anual de crescimento do PIB de 4\%, contra 2,7\% para a CE entre 1986 e 1992, levando a uma melhoria relativa do PIB per capita de 4,7 pontos.

b) Um acréscimo da produtividade global sensivelmente superior à média da CE: de $3,8 \%$ ano, contra $1,7 \%$ na CE;

c) Um acréscimo ou crescimento muito acentuado do investimento directo estrangeiro, que passou de 2\% da FBCF em 1980 para 14\% em 1990;

d) Um ganho de 400000 postos de trabalho (dos quais 175000 na indústria ou sector secundário), com descida da taxa de desemprego de $8,3 \%$ para cerca de 4 e $1 / 2 \%$ em 1992. 
Quadro III

EVOLUÇÃO ECONÓMICA — 1986/92

\begin{tabular}{|l|c|c|}
\hline & Portugal & CE \\
\hline & \multicolumn{2}{|c|}{ Taxa média de variação } \\
\hline PIB & 4.0 & 2.7 \\
Produtividade global & 3.8 & 1.7 \\
Preços (1992) & 9.0 & 4.6 \\
Salários nominais & 16.9 & 6.3 \\
Salários reais & 5.0 & 1.8 \\
& & \\
CTUP & 12.6 & 4.5 \\
Nominal & -1.0 & -0.5 \\
Real & 5.5 & 3.6 \\
Relativo & \multicolumn{2}{|c|}{ Percentagens, 1992 } \\
\hline & 25.0 & 20,0 \\
Investimento/PIB & 20.1 & 14.0 \\
Poupança/Rend. disp. & 4.2 & 9.6 \\
Desemprego/Pop. activa & \multicolumn{2}{|c|}{} \\
\hline
\end{tabular}

Fonte: EUROSTAT, CE

O período que se sucedeu à nossa entrada na CEE, porém, caracterizou-se por um comportamento particularmente favorável da envolvente externa, com uma baixa acentuada dos preços do petróleo em 1986, a queda do dólar e uma baixa das taxas de juro, tendo a nossa economia beneficiado de uma melhoria sensível dos termos de troca ou relação entre os preços dos produtos exportados e os dos produtos importados.

No que toca ao comportamento sectorial verificou-se que o crescimento da produção foi, no início (1985/90), bastante polarizado nos sectores tradicionais: têxtil, vestuário, calçado, madeira e cortiça - o que corresponde ao padrão referido, de reforço da estrutura existente, em que os sectores excedentários se tornaram mais excedentários ainda.

Revelou-se, entretanto, a debilidade de dois pólos tradicionais importantes da nossa produção: as fileiras têxtil e florestal, com perda de quota de mercado tanto no mercado interno como nos mercados externos e perda de quota do mercado interno por parte da indústria alimentar.

Ao mesmo tempo aumentou consideravelmente a taxa de penetração das 1.4 importações na procura interna (18 pontos), passando de $26 \%$ a $44 \%$, enquanto a 
taxa de penetração nos mercados externos se elevava de 15 pontos (passando de $20 \%$ a $36 \%)$.

O peso da economia portuguesa no conjunto da economia comunitária elevou-se, no período de $1986 / 92$, de $0,8 \%$ para $1,2 \%$ em termos de produto medido em ECUs correntes.

O mesmo sucedeu com a indústria, cuja posição no contexto comunitário se reforçou em termos de produção, passando de cerca de 1,5\% do total em 1985 para cerca de $1,8 \%$ em 1992. Tanto não sucedeu em termos de emprego em virtude da redução do diferencial de produtividade entretanto conseguida.

\section{Gráfico I}

PESO DA INDÚSTRIA PORTUGUESA NO CONTEXTO COMUNITÁRIO (1985-1992)

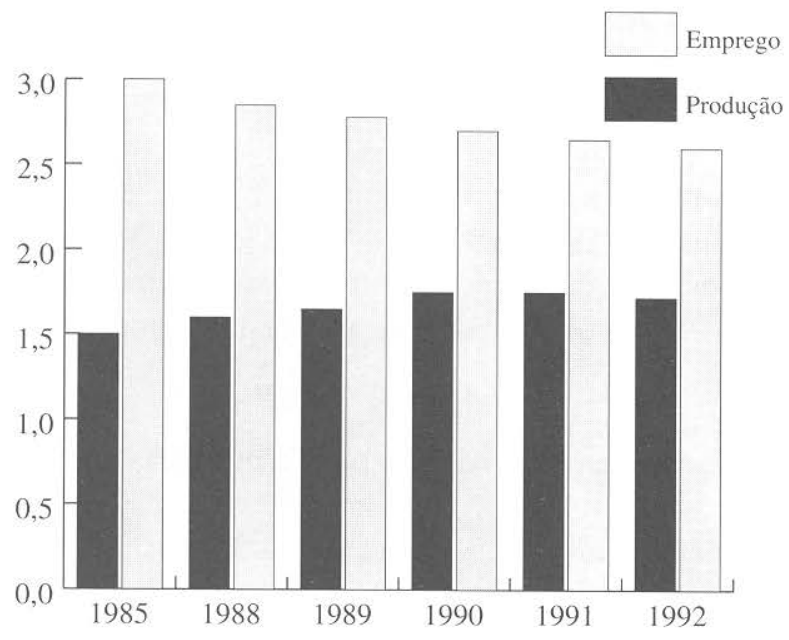

A melhoria de posição, em termos de produto da indústria portuguesa no conjunto comunitário, revela também a mencionada tendência para o reforço da estrutura ou especialização produtiva existente, uma vez que o principal contributo para essa melhoria proveio de sectores tradicionais como o têxtil, o vestuário e calçado, com relevo para este último, cujo peso relativo quase duplicou, passando de 3,5\% em 1985 para 6,5\% em 1992. Ao contrário, as indústrias química e do material de transporte viram a sua quota, na produção dos respectivos sectores da Comunidade, reduzir-se.

A melhoria de posição da produção industrial portuguesa na da Comunidade, porém, circunscreveu-se ao período de 1985/89, passando depois a reduzir-se, o que leva a pôr o problema de saber se não tenderá no futuro a inverter-se a tendência para um ganho de posição relativa. Não é, todavia, possível afirmá-lo, em 
virtude dos factores de natureza cíclica envolvidos na evolução observada em Portugal e na Europa nos três últimos anos.

Melhoria acentuada de posição relativa em termos de produção verificou-se no valor acrescentado da nossa indústria extractiva em comparação com a da União Europeia. Aí, porém, o reforço da posição da nossa indústria é realçado pela situação de estagnação que a indústria extractiva da Comunidade revelou ao longo de todo o período.

Em termos relativos, e de especialização produtiva, Portugal reforçou o seu índice de especialização nos sectores do vestuário, minerais não metálicos, máquinas eléctricas e calçado e reduziu o seu índice de especialização nos sectores da madeira e cortiça, material de transporte e química.

Entretanto o investimento directo estrangeiro elevou-se acentuadamente, tendo-se o investimento da indústria concentrado em larga medida nas indústrias metálicas, químicas e de material de transporte, e verificado um reforço do controlo do capital estrangeiro em certos sectores, passando este às seguintes posições de domínio na exportação:

- $90 \%$ nas exportações de metais não ferrosos;

- $85 \%$ nas exportações de componentes para automóveis;

- 56\% nas exportações de componentes para pasta de papel;

- $52 \%$ nas exportações de componentes para resinas sintéticas.

\section{Que tipo de especialização produtiva para a indústria portuguesa?}

Notámos que, numa primeira fase, a integração de economias industrialmente menos avançadas com outras mais evoluídas tende a reforçar o padrão ou tipo de especialização produtiva dominante nas primeiras, em virtude da exploração das vantagens competitivas existentes.

Com o tempo, porém, este modelo tende a esgotar as suas potencialidades, especialmente se o mesmo se basear na exploração das vantagens que lhe oferecem os baixos custos de uma mão-de-obra menos qualificada. Este processo acentua-se no quadro de uma união monetária, por deixar de existir aí o instrumento do ajustamento de paridades para ganhar competitividade ou repor a competitividade perdida por essas economias.

Ao aderir ao MTC do Sistema Monetário Europeu e, mais ainda, à união monetária renuncia-se, de algum modo, a um modelo do desenvolvimento baseado essencialmente no baixo custo da mão-de-obra, para optar por um outro característico dos países industriais, que aposta no "catching up" tecnologico, na operação das empresas em vastos mercados integrados e na inovação e diversificação produtiva. 
Neste segundo modelo, muito mais dinâmico, as empresas nacionais, em vez de se concentrarem no mercado interno, passam a procurar explorar as economias de escala que lhes oferece o mercado integrado e a orientar toda a sua estratégia de concepção, design, produção e distribuição para esse novo quadro.

O tipo de comércio que tendem a realizar com os demais países é de trocarem com eles o mesmo tipo de produtos que esses países produzem e designa-se por comércio intra-industrial - por oposição do comércio inter-industrial, que supõe especializações produtivas distintas.

A integração de economias em estádios semelhantes de desenvolvimento num mercado mais vasto tende a promover o desenvolvimento do comércio intra-industrial. Pelo menos foi essa claramente a experiência da EFTA ${ }^{2}$.

O mesmo não sucede necessariamente, ou pelo menos no mesmo grau, no caso da integração de economias em estádios muito diferentes de desenvolvimento e com estruturas produtivas distintas.

Duas possibilidades ou cenários se apresentam neste caso aos países com estruturas produtivas menos evoluídas e diversificadas, como no caso português.

O primeiro consiste em prosseguir na via da especialização interindustrial, apostando nos sectores em que dispõem já de uma vantagem comparativa em relação aos países mais desenvolvidos do centro e norte da Europa, nomeadamente nos têxteis, vestuário e calçado, produtos metálicos e outros.

O segundo consiste em ir reforçando progressivamente a posição das indústrias com um maior valor acrescentado e conteúdo tecnológico mais elevado, aproximando-nos da estrutura dos países industrialmente mais evoluídos. É o chamado cenário intraindustrial.

O primeiro cenário apresenta sérios riscos com a abertura da Comunidade ao exterior - nomeadamente com o desmantelamento do Acordo Multifibras decidido nas últimas negociações do GATT. Com efeito, essa abertura expõe os nossos sectores tradicionais à concorrência de países como a Índia e o Paquistão, cujos salários rondam $1 / 4$ a 1/5 dos nossos, ao mesmo tempo que representa uma aposta em sectores com um reduzido crescimento da procura.

O segundo cenário é manifestamente superior, sem que isso implique pura e simplesmente o abandono dos sectores tradicionais. Estes, ao contrário, deverão ser objecto de um "upgrading" da produção, retendo e desenvolvendo aqueles segmentos mais exigentes como tem feito a Suíça com o sector têxtil.

A importância relativa destes sectores ir-se-á, todavia, reduzindo gradualmente, enquanto outros, de tecnologias mais avançadas, aumentam o seu peso no produto industrial.

Esta transformação, porém, reclama alterações na forma de operar e nas estratégias, tanto internas como externas, das nossas empresas.

Elas terão, antes de mais, de perspectivar a sua actuação no quadro do mercado comunitário, ou mesmo mundial, e não apenas no do mercado nacional, e pensar 
toda a sua estratégia em termos de produção, marketing e distribuição, nesse quadro mais amplo. O mesmo se diga da política de alianças, fusões e aquisições, de I\&D e das tecnologias adoptadas.

$O$ investimento estrangeiro $\mathrm{e} o$ efeito de demonstração que pode exercer nas empresas de controlo nacional pode aqui ter um papel importante. Importa, porém, não cair no vício irlandês, de centrar a política de incentivos na atracção desse investimento em projectos isolados do investimento interno, desenvolvendo na indústria uma estrutura dualista, com os sectores de ponta controlados por estrangeiros e um sector tradicional em declínio, controlado por nacionais.

Para que a transição para um modelo intraindustrial se mostre possível é também necessário apostar seriamente na qualidade e relevância do ensino ministrado nas escolas e nas acções de formação e treino de mão-de-obra.

O nosso baixo nível de desenvolvimento andou sempre associado "à pobreza em capital humano, reflectida pelo baixo nível educacional, de saber técnico e de receptividade à inovação da população portuguesa"3.

Ora constitui um facto posto em relevo por todos os estudiosos do desenvolvimento o de um dos factores ou ingredientes sempre presente nos "saltos", do desenvolvimento, seja no Japão, seja nos "tigres" asiáticos, bem como os avanços tecnológicos ocorridos em países como a Suíça em determinadas épocas, ser uma "revolução" na educação.

Entre nós o panorama educativo, seja no que se refere a taxa de analfabetismo, seja a taxas de escolaridade ou no acesso ao ensino superior alterou-se profundamente nos últimos anos, aproximando-se os nossos indicadores cada vez mais dos níveis dominantes na Europa.

Esse progresso não se reflecte ainda inteiramente no nível de qualificação da nossa mão-de-obra que é considerado dos mais baixos da União Europeia. Mas há-de vir a reflectir-se gradualmente.

Um aspecto relevante, porém, é o de saber se a qualidade e relevância do ensino ministrado, tanto nas escolas como nas acções de formação e treino de mão-de-obra, que a ajuda dos fundos comunitários nos tem permitido multiplicar, são as mais adequadas. 


\section{Quadro IV}

A EDUCAÇÃO EM PORTUGAL E NA CE (FINAL DOS ANOS 80)

\begin{tabular}{|c|c|c|c|c|c|}
\hline & Portugal & $\mathrm{CE}$ & & Portugal & $\mathrm{CE}$ \\
\hline Educação & & & Cultura & & \\
\hline Taxa de analfabetismo (1990) & 11.9 & (a) 4.8 & Livros editados/milhão de habit. (1990)) & 666 & (b) 1063 \\
\hline \multicolumn{6}{|l|}{ Efectivos escolares e universitários } \\
\hline$\%$ do grupo etário 5-24 anos & 61 & 69 & Circulação & & \\
\hline Taxa bruta de escolarização (1986) & & & Períodicos e revistas/1000 habit. (1990) & 618 & (b) 5048 \\
\hline $2 .^{\circ}$ nível de escolaridade & 59 & 84 & Jornais diários/1000 habit. (1990) & 38 & (c) 395 \\
\hline 3. ${ }^{\circ}$ nível de escolaridade & 18.4 & 23.5 & Bibliotecas/milhão de habit. & 298 & (d) 414 \\
\hline Escolaridade obrigatória (n. ${ }^{\circ}$ anos) & 9 & $8-12$ & Import. material leitura per capita (US\$) & 6.5 & (b) 11.1 \\
\hline N. ${ }^{\circ}$ raparigas por 100 rapazes $(1988 / 89)$ & & & Cinema (1987) & & \\
\hline no $2 .^{\circ}$ nível de escolaridade & 114 & 98 & N. ${ }^{\circ}$ sessões/habitante/ano & 1.7 & (d) 11.1 \\
\hline no $3 .^{\circ}$ nível de escolaridade & 108 & 90 & & & \\
\hline \multicolumn{6}{|l|}{ Desp. famílias em educação (1986) } \\
\hline (\% do consumo total) & 5.7 & 8.5 & & & \\
\hline
\end{tabular}

(a) Média: Grécia, Itália e Espanha (est. da UNESCO)

(b) Alemanha (1989)

(c) Reino Unido (1988)

(d) França (1989)

Fonte: EUROSTAT 


\section{CONCLUSÕES}

Em face da evolução verificada e dos desafios e condicionantes que se nos deparam que futuro podemos legitimamente antecipar para a economia portuguesa no quadro da união económica e monetária?

A história, mesmo a recente, é fertil em exemplos de países que, após terem conhecido níveis relativos de bem estar elevados e períodos de expansão acentuada, atravessaram fases de estagnação ou de declínio que os levaram a perder as posições conquistadas ${ }^{4}$. Para além disso, no mundo de globalização, interdependência e agressividade concorrencial em que vivemos nada pode considerar-se adquirido.

Em termos de crescimento relativo e de níveis de bem estar, porém, a história da nossa integração na economia europeia e do seu aprofundamento tem-se mostrado claramente positiva.

O fosso que nos separa dos países mais prósperos do centro e norte da Europa cavou-se sobretudo entre os meados do século XIX e a $1^{\text {a }}$ Guerra Mundial ${ }^{5}$.

$O$ período entre as duas guerras foi, em larga medida, de perturbações e estagnação, tanto nos países do norte como nos países periféricos, não se tendo verificado alteração significativa dos níveis de bem estar relativo dos dois grupos de países. No caso específico de Portugal verificou-se mesmo uma acentuação do desnível de rendimento, de 45\% do dos países desenvolvidos em 1913 para 37\% em 1950. A partir dos anos 50, porém, o panorama é de manifesta convergência real até ao primeiro choque petrolífero em que, como se notou anteriormente, o nosso rendimento per capita expresso em termos de poder de compra passou de 1/5 para 2/5 do dos Estados Unidos.

Após uma década de retrocesso, entre meados dos anos 70 e meados dos anos 80, em que, além do efeito negativo dos dois choques petrolíferos Portugal sofreu as peturbações ocorridas no sistema produtivo após a Revolução de 1974, com as nacionalizações, a descolonização e a absorção de 600000 a 800000 retornados, observou-se de novo um movimento de retoma da convergência real da nossa economia em relação à da União Europeia.

Se compararmos o nosso rendimento per capita em termos de poder de compra com o dos Estados Unidos, podemos verificar que ele passou de cerca de $20 \%$ daquele em meados dos anos 50 para cerca de $45 \%$ em 1993 . Tendência semelhante se verificou em relação à média da União Europeia e dos países da OCDE.

Vai esta convergência continuar ou, ao contrário, vai a abertura do nosso mercado à concorrência do exterior, com a agressividade das chamadas "economias emergentes" da Ásia e da América Latina e o fortalecimento da posição competitiva das economias em transição do Leste Europeu, sustê-la ou mesmo invertê-la? 
Não temos resposta segura para esta pergunta. Mas é de crer que as transferências comunitárias e o aumento do investimento directo estrangeiro nos permitam, se bem utilizados, reduzir os chamados "custos" de periferia e ir transformando gradualmente a estrutura do sistema produtivo português, de modo a torná-lo capaz de fazer face aos choques e desafios com que somos confrontados.

Quanto à união monetária em perspectiva não dispomos de experiência vivida de que possamos tirar conclusões.

Entretanto, no que toca aos efeitos sobre a produção e o emprego que dela possam resultar as conclusões são ambíguas. No que respeita aos fluxos de trocas o seu principal efeito consiste em eliminar os custos de conversão no comércio intra-comunitário. O que, contribuindo para tornar os nossos produtos mais competitivos nos mercados externos, torna também os bens provenientes da UE mais atractivos para os consumidores portugueses.

No que se refere aos fluxos de investimento os efeitos da unificação monetária deverão, em princípio, ser positivos uma vez que a moeda única elimina o prémio de risco de câmbio nas taxas de juro, contribuindo por essa forma para uma redução destas últimas. E uma tal redução, por seu turno, benificia também o investimento fixo interno, contribuindo a eliminação do prémio de risco para alterar favoravelmente a relação das taxas de juro suportadas pelos países periféricos, com as dominantes nos princípais mercados do centro e norte da Europa.

Ao aderir à união monetária, entretanto, Portugal perde a possibilidade de recorrer à desvalorização monetária como forma de ganhar competitividade. Esta possibilidade, porém, só tem efeitos positivos quando os salários são flexíveis e os trabalhadores se mostram dispostos a sofrer uma redução do seu nível de vida. Numa pequena economia aberta como a nossa, os aumentos de preços resultantes da desvalorização da moeda penetram rapidamente toda a economia, sendo difícil conter as pressões no sentido duma subida de salários.

Entretanto a diferença de estruturas económicas entre o Norte e o Sul expõe os países do Sul ao impacto da assimetria dos choques (como no caso dos dois choques petrolíferos), especialmente quando não existe um sistema fiscal que compense os efeitos dessa assimetria por meio de tranferências do centro para a periferia como nos Estados federais.

Este inconveniente tenderá naturalmente a esbater-se, na medida $\mathrm{em}$ que as estruturas das economias periféricas se aproximem das dos países do centro e norte. $O$ que pressupõe a obtenção de sucesso na adopção pelos países periféricos do aludido modelo intra-industrial de desenvolvimento.

Conseguiremos nós esse sucesso?

Uma vez mais importa afirmar a nossa convicção profunda de que a variável estratégica aqui é a educação.

$\mathrm{Na}$ economia global e concorrencial de um mundo sem fronteiras para que tendemos, caracterizada por uma elevada instabilidade, os choques a que nos expõe 
a envolvente externa são inevitáveis. No que diferem os países é na capacidade para responder a esses choques. E essa capacidade depende sobretudo da preparação de empresários, gestores, quadros e da mão-de-obra em geral, impondo-se a verdade da afirmação de Daniel Stoleru: "Num mundo em que produtos, capitais e tecnologias circulam livremente, são os homens que fazem a diferença".

É com estes, e com a sua transformação, que temos de contar para responder aos desafios de um mundo integrado, concorrencional e agressivo como aquele em que vivemos.

\section{NOTAS}

1. Neste mesmo sentido vide: Barry Eichengreen, «European Monetary Unification», in Journal of Economic Literature, vol. XXXI, n. ${ }^{\circ}$ 3, Setembro de 1993, p. 1321-1357.

2. Vide, sob este ponto, Amund Utne, The EFTA Countries Export Performance for Manufactured Goods - 1970-1982, EFTA Occasional paper n. ${ }^{\circ}$ 7, Genebra, 1984.

3. Cf: Jaime Reis, "O atraso económico português em perspectiva histórica (1860-1913)", em Análise Social, vol. XX (80) 1984 p. 7 a 28, onde se nota que em 1910 a taxa de analfabetismo em Portugal (de 70\%) era das mais elevadas da Europa e que a taxa de escolarizaçao era um terço apenas da de países como a Hungria e a Dinamarca, enquanto já em 1850, 90\% dos Suecos sabiam ler e escrever.

4. Um dos casos paradigmáticos é o da Argentina que, tendo conhecido no começo do século níveis de rendimento muito próximos dos da Suíça, experimentou depois uma longa e profunda fase de declínio. Nos últimos anos, porém, está de novo a demonstrar um sucesso considerável em matéria de crescimento sustentado.

5. Vide sobre este ponto P. Bairoch, "Europe Gross National Product 1800-1975", in Journal of European Economic History, Vol 5, p. 273-340 e o artigo citado de Jaime Reis, em Análise Social. 